\title{
Evaluating and forecasting performance using past data of an industry: An analysis of electronic manufacturing services industry
}

\author{
Thanh-Tuyen Tran* \\ Scientific Research Office, Lac Hong University, Bien Hoa City, Dong Nai, Vietnam
}

\section{A RT ICLE INFO}

\section{Article history:}

Received 5 September 2016

Received in revised form

12 November 2016

Accepted 18 November 2016

\section{Keywords:}

EMS industry

Performance efficiency

Grey forecasting

Data envelopment analysis

\begin{abstract}
A B S T R A C T
In this paper, the slacks-based measure of super efficiency (super-SBM) is employed to evaluate the rankings and identify the best performers among 18 chosen EMS providers. Both profitability and marketability efficiency are concerned in order to give a comprehensive view in performance of these companies. Besides, Non-radial Malmquist is also applied to analyze the inter-temporal efficiency change which is decomposed into "catch-up" and "frontier-shift" effects. In addition, GM $(1,1)$ will be utilized for forecasting the future variables which give the managers a further look on the development potential and situation of these EMSs in near future. The results found that the number of efficient companies and the order of ranking change every year. Hon Hai seems to keep its highest best rankings among 18 DMUs most of the time regarding performance scores. In recent years and next few years, the efficiency of profitability stage is higher than in marketability when considering each separate year with super SBM model. However, there are more companies showing efficient score on marketability model than on profitability in cross - period performance with Malmquist index, which means that the increasing market value productivity of EMSs have been being more and more improved. Finally, a decision-making matrix will be designed to help EMS authorities identify their status and position in the industry. Some recommendations for EMSs in how to enhance precisely its performance to create company value and success are also suggested here. The integration of Data Envelopment Analysis (DEA) and Grey model this research is expect to contribute a better insights into performance evaluation of EMSs in recent years and next few years.
\end{abstract}

(C) 2016 The Authors. Published by IASE. This is an open access article under the CC BY-NC-ND license (http://creativecommons.org/licenses/by-nc-nd/4.0/).

\section{Introduction}

Due to the rapid advancement in technology, competition among EMS providers is becoming tougher. Especially in the current trend of economic globalization and integration of countries around the world, the competition is hard in gaining market share. Like all other businesses, EMSs has probably faced with a great amount of challenges and obstacles from time to time. First of all, the demand of customers is increasing rapidly. They asked for the customized products with reasonable cost. This puts much pressure on electronics providers to think of ways to meet the demands. Secondly, it is complicated for EMS providers to estimate customer

\footnotetext{
* Corresponding Author.

Email Address: copcoi2@gmail.com

https://doi.org/10.21833/ijaas.2016.12.002

2313-626X/@ 2016 The Authors. Published by IASE.

This is an open access article under the CC BY-NC-ND license

(http://creativecommons.org/licenses/by-nc-nd/4.0/)
}

demand, which requires them, must be close to customers and must work with retailers and resellers to better understand markets needs and demand. Thirdly, it is essential for electronic providers to produce components with performance and functionality at reasonable price to keep high competitiveness in challenging environment. The fourth challenging is the different between supply and demand. The providers not only have to produce new products, redesign the old components but also estimate the changes on the demand of customers, which make up a high strain on electronics manufacturing providers. Fifthly, machinery, equipment, technology, and labor skills are the most important issues which require provider take care of and improve all the time to catch up with the rapid world's innovation. Especially, labor cost is becoming more competitive. This sector requires a large number of workers; therefore the companies have to compete directly with each other to attract employees. On the other side, it could be possible 
that in the future labor cost is getting less important when there is more demand for technical skills.

International's Global Manufacturing Outlook (GMO) 2014 found out Top 5 biggest challenges that electronic manufacturers have to deal with. In general, increasing competition, volatile energy and input costs, new technologies and supply chain visibility are all creating immediate challenges for organizations. In details, $39 \%$ of respondents say that their biggest challenge stems from intense competition and pressure on prices. 25\% of companies found that efficiency in research and development is their biggest challenges. Keeping the business model competitive is a most challenging for $30 \%$ of EMS providers. $32 \%$ and $23 \%$ EMS respondent consider IT system keeping pace with demand and managing geopolitical risk as their biggest challenges.

The challenges above require the EMS providers evaluate the rapidly changing innovation and develop a strategy for how they fit into it. To do this, the first issue they have to consider is their operation efficiency, their competitive ability and their position in the industry from past to future to find out the best developing strategies.

At present, EMSs have many opportunities for developing but also have to face several significant problems such as: how to maintain their competitiveness in fierce markets, how to expand scale, to diversify products, and divert from processing into other forms which can bring more advantages to the company. Under a highly competitive market and dynamic industrial environment, it is essential for organizations to know how efficiently and effectively they are operating compared to similar organizations. In other words, managers should know their position in the industry, their strength and weakness to find the ways and directions to enhance the company operational performance. In addition, the investors also need to know the performance of enterprises that they have interest to invest. In this research, the author try to help the EMSs executive and investors to have an overall look of enterprises' operation performance efficiency from past to future.

The purpose of this research is to combine the Grey Model (GM) and the Data envelopment analysis (DEA) to evaluate the performance efficiency of 18 EMSs in recent year (2012-2014) and next few year (2015-2017) to help the providers' executive have an overall look on their profitability and marketability efficiency from past to future. This paper ranks the best performers among EMSs by using Super SBM and measure the variation in productivity in the cross-period by using the Malmquist non-radial approach. At the same time, the author also designs a managerial decision making matrix and suggests some managerial implications for improving operational efficiency for 18 chosen EMS providers.

\section{Methods}

\subsection{Two-stage production model}

The performance of 18 EMSs companies is assessed based on the two stage production model which initially proposed by Seiford and Zhu (1999). In this research, the profitability and marketability efficiency are calculated independently and separately with the two DEA models which are super SBM and Malmquist. The two stage production model using in this research is shown in Fig. 1.

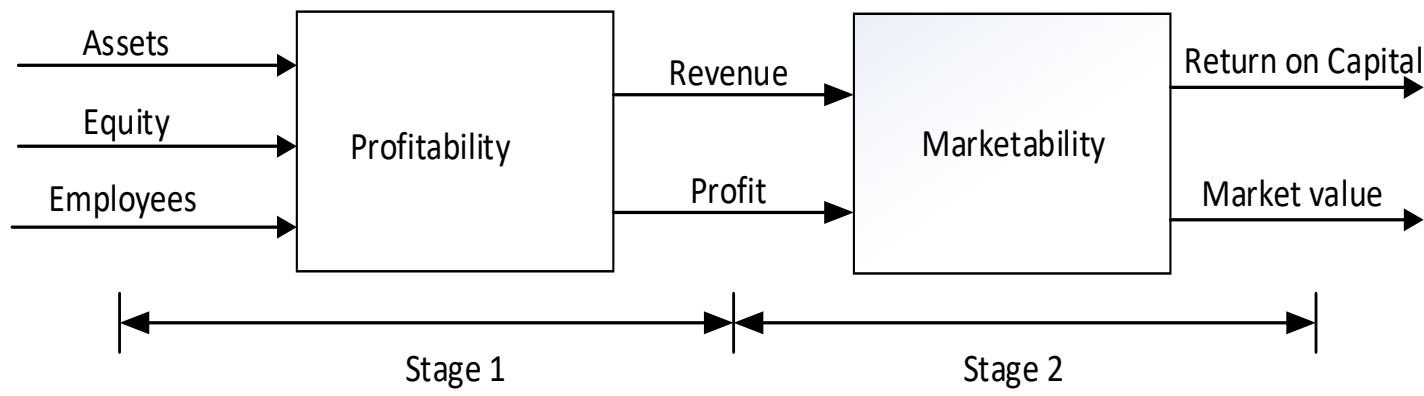

Fig. 1: Profitability and marketability efficiency models for EMSs

Profitability indicates the ability of generating profit and marketability is market value increasing ability. The profitability of an EMS provider as seen by shareholders is calculated in the first stage with three inputs: employees, assets and equity that produce outputs revenue and profit. The marketability of those companies as seen by stock investors is measured in the second stage by using two inputs revenue and profit that produce two outputs: market value and return on capital. There are two intermediate products, revenues and profits, which are the outputs of the first stage as well as the inputs of the second stage. The efficiencies of the first stage (profitability) and second stage (marketability) are calculated separately via two independent DEA models for ranking and assessing the efficiency of EMSs. Decomposition of the production process also can help to identify the source of inefficiency in operation of enterprises.

\subsection{Research development}

This study uses GM $(1,1)$ and DEA model as the foundation of a set of forecasting and measuring the efficiency models. The research development in this paper is implemented in EMS industry and also 
selects all related documentations as references. The contents of Fig. 2 are described as follows. There are four stages. The first stage is data collection and the second stage is data manipulation. Integration and evaluation is in the third stage. The analysis and conclusion is the last stage.

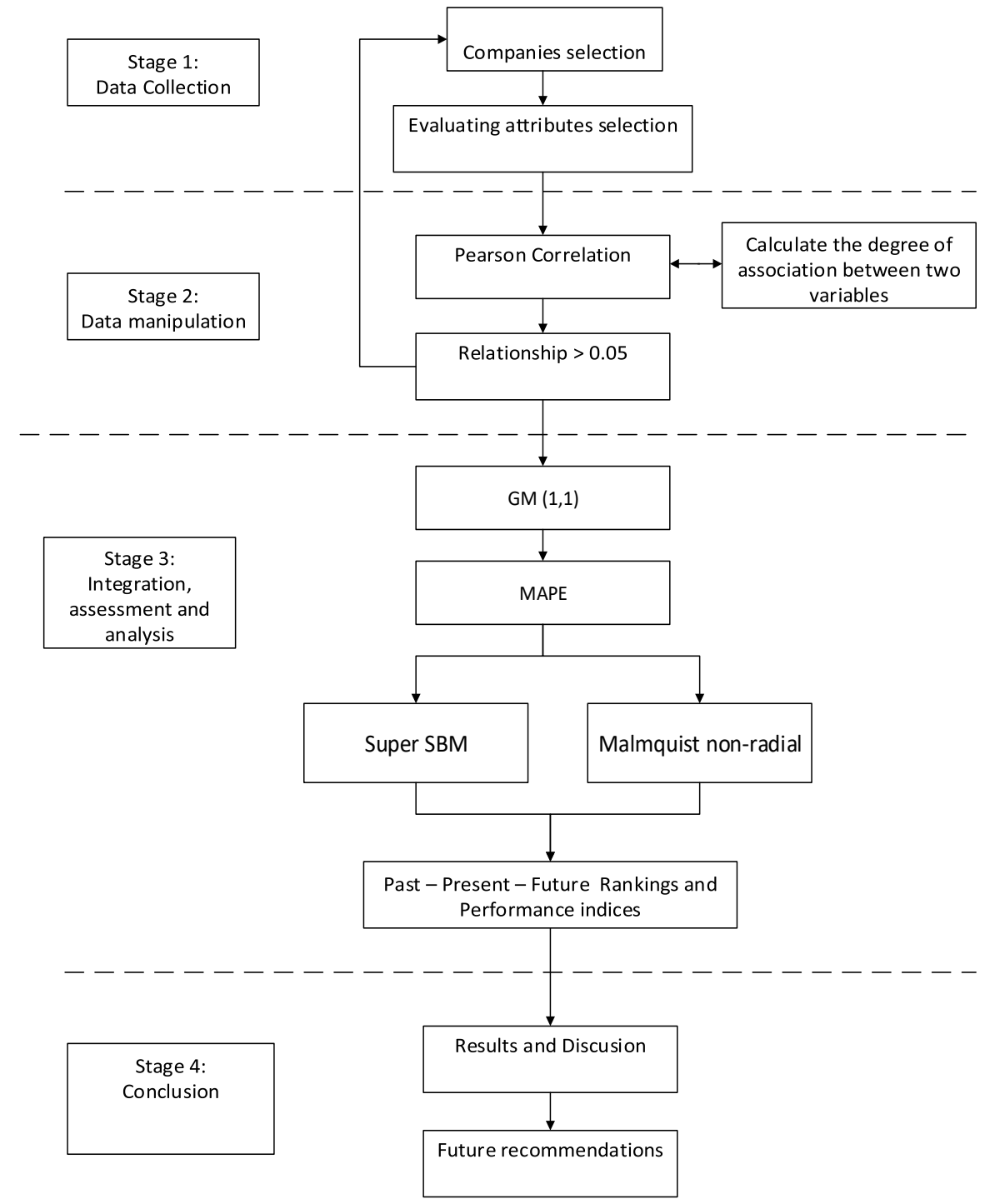

Fig. 2: Research development

\subsubsection{The first stage with two steps}

Step 1: Choose the Decision-making unit: Referring to related literatures on DEA, Grey theory and then the researcher determined the subject and which approach this paper will use.

The researchers investigate EMS related enterprises to find all potential candidates to be DMUs list. 18 EMS manufacturers in the MMI Top $50^{\mathrm{TM}}$ list of the world's largest EMS providers in 2014 in which firms published their financial statement in Bloomberg stock market during the period 2012 to 2014 were selected. And from the point of view of integrating the use of explicit and implicit knowledge, it is worthwhile to assess the efficiency of these candidate companies. The business efficiency of the company in case and the candidate companies can be easily obtained through the use of the DEA Solver software by Saitech in 1999.

Step 2: Choose input/output variables: It is said that DEA is a sensitive tool. Therefore, before using it, choosing inputs and outputs very thoroughly is necessary because the selection of input and output variables will influence on the correction of final efficiency or not. It is better to have wider range of input and output variables to analyze, but too many variables will dilute the variation among DMUs, leading to insensitivity of benefit analysis. Therefore, this paper considers the following critical factors in selecting input and output items: related literature discussion or necessary variables selected in factor analysis method; Pearson correlation coefficient for testing the correlation and significant level between inputs and outputs. Input/output items must correspond to units to evaluate; the data has public trust and each variable can be quantified for analysis. If significant level of the two-tailed test is larger than 0.05, they satisfy the isotonicity requirement. Otherwise, we go back to step 1 and choose new decision making unit again until it meets the criteria. 


\subsubsection{The second stage (data manipulation)}

Step 3: Pearson correlation: The formulation of DEA is to measure the efficiency of each decision making unit by constructing a relative efficiency score via the transformation of the multiple inputs and outputs into a ratio of a single virtual output to a single virtual input. Therefore, to test the data whether match with the basic assumptions of DEA methodology or not, correlation analysis of variables is calculated to verify for positive relationship between the selected inputs and outputs. If the variables with the negative coefficient, they need to be removed, then we will go back to step 2 of the selection process to re-do the variable selection until they can satisfy the condition. In this study, the Pearson Correlation Coefficient Test is employed.

\subsubsection{The third stage (integration, assessment and analysis)}

Step 4: Grey prediction: Grey Prediction has based on grey model GM $(1,1)$ to predict the data values from 2015 to 2017. However, the forecast always exist error. Therefore, in this study the MAPE is applied to measure the forecasting error.

Step 5: Forecasting accuracy: It is difficult to expect that forecasts will effectively be right most of time. Therefore, the MAPE (Mean Absolute Percent Error) is employed to measure the prediction accuracy. If the forecasting error is too high, the study has to reselect the inputs and outputs.

Step 6: Choose the DEA model: After the high correlation of the input and output are determined for the 18 companies in this study, these data are manipulated using DEA model .In this paper, the software of DEA-Solver is employed to calculate profitability and marketability separately and independently withsuper-SBM model and Malmquistnon radial. The efficiency measuring by ranking DMUs' performance is then achieved.

The Super SBM model first proposed by Tone (2002) is an appropriate version of DEA for ranking these efficient EMS companies in this study. This model is employed to show how efficiency can be provided for each efficient unit in comparison to other DMUs.

Malmquist index is further used with the multiphase, efficient frontier data to assess their performance, analyze their technical efficiency, analyze their position, and recommend the integration solution for each company from past to future.

\subsubsection{The fourth stage (conclusion)}

Step 7: Results analysis: This section summarizes the assessment and ranking results for the Decisionmaking units and them utilize explicit and implicit knowledge to correct the shortcomings of horizontal and vertical integration so that managers can enhance the competitiveness of the enterprise.
Step 8: Conclusions and recommendations: This paper implements the Super SBM and non- radial Malmquist productivity index to measure the efficiency of profit generating and market value increasing of EMSs. We used the Malmquist productivity index to compute in order to evaluate the productivity change of a DMU between two time periods. Suitable recommendations are given and conclusions and future research directions are summarized in this part.

\section{Analyses and results}

\subsection{Collect the DMUs}

Electronic manufacturing services (EMS) are located throughout the world with thousands companies varying in terms of production capacities and comply with various quality standards and regulatory requirements. After doing the survey the EMS market segments, the study finds out 18 enterprises which are in the MMI Top world 50 largest EMS providers in 2014. Although fifty leading industrial enterprises all over the world were published in 2015, the analysis was only conducted on the 18 companies which are stable in market and can provide the completely data for 4 consecutive years (2011-2014) in Bloomberg Business week news, which is an available, reliable and valid to the public. List of companies considered in the sample are publicly listed so its complete information is easy to collect. According to Golany and Roll (1989), when applying DEA, the number of DMUs should be at least twice the total number of input and output variables considered. In this research, the author will investigate the efficiency of 18 EMSs which is more than twice the five factors selected for the profitability performance model. In this regards, the DEA model developed based on the profitability performance model has met construct validity requirement. By adopting the same regulations, the marketability model in this study is also found on a required validity issue. Moreover, these 18 companies play major roles in the EMS industry and can represent for whole industry in stock market. Therefore, the selection of these 18 candidates is qualified.

\subsection{Grey forecasting model}

Predicting and analyzing the developing trend in future based on past facts is one of the great ways keeping enterprises competitive with other competitors (Nguyen et al., 2015). Various forecasting methods have been proposed in the last few decades. This theory is an approach in which a model is created with limited samples to provide better forecasting advantage for short-term problems. Although, Grey theory just needs few input and output data to construct Grey model, it is required to have at least four successive years for forecasting (Deng, 1989). In this paper, the author 
use the data from 2011 to 2014 when applying GM $(1,1)$ to forecast the input and output variables of EMS providers from 2015 to 2017. To explain how use Grey GM(1,1) to forecast the data from the exited data sequence, the data at the first column (Assets) in the Table 1; used in this section. Other data then can be calculated similarly.

Table 1: Inputs and outputs factors of DMU1 in period of 2011-2014

\begin{tabular}{|c|c|c|c|c|c|c|c|}
\hline $\begin{array}{c}\text { Hon Hai Precision } \\
\text { Industry Co. } \\
\begin{array}{c}\text { Technology Co } \\
\text { Ltd }\end{array}\end{array}$ & $\begin{array}{c}\text { (I)Assets } \\
\text { (Millions } \\
\text { of US } \\
\text { Dollars) }\end{array}$ & $\begin{array}{c}\text { (I)Equity } \\
\text { (Millions } \\
\text { of US } \\
\text { Dollars) }\end{array}$ & $\begin{array}{c}\text { (I)Employee } \\
\text { (person) }\end{array}$ & $\begin{array}{c}\text { (O)Revenues } \\
\text { (Millions of } \\
\text { US Dollars) }\end{array}$ & $\begin{array}{c}\text { (O)Profits } \\
\text { (Millions } \\
\text { of US } \\
\text { Dollars) }\end{array}$ & $\begin{array}{c}\text { (0)Return } \\
\text { on Capital } \\
\text { (\%) }\end{array}$ & $\begin{array}{c}\text { (O)Market } \\
\text { value (Mil } \\
\text { USD) }\end{array}$ \\
\hline 2011 & 55664.10 & 19772.9 & 1001000 & 110969.2 & 8561.5 & 14.1 & 29271.2 \\
\hline 2012 & 65976.7 & 21891.4 & 1300000 & 125519.4 & 8043.0 & 14.7 & $36,228.0$ \\
\hline 2013 & 74415.0 & 25910.5 & 1097000 & 127027.5 & 8185.9 & 15.5 & $35,271.2$ \\
\hline 2014 & 79250.2 & 31657.4 & 1061000 & 135411.4 & 9383.1 & 16.88 & $41,098.01$ \\
\hline
\end{tabular}

The procedure is carried out step by step as follows. First, the researcher uses the $\operatorname{GM}(1,1)$ model for trying to forecast the variance of primitive series:

Step 1: From the second column in the Table 2, the original sequence $\mathrm{X}^{(0)}$ is:

$X^{(0)}=\{55,664.10 ; 65,976.70 ; 74,415.00 ; 79250.20\}$

Step 2: From $X^{(0)}$ sequence, the Accumulated generation operation (AGO) can be achieved as follows:

$X^{(1)}=\left\{x^{(1)}(1), x^{(1)}(2), x^{(1)}(3), x^{(1)}(4)\right\}$

$\{55664.10,121640.80,196055.8,275306\}$

where,

$x^{(1)}(1)=x^{(0)}(1)=55664.10$

$x^{(1)}(2)=x^{(0)}(1)+x^{(0)}(2)=121,640.80$

$x^{(1)}(3)=x^{(0)}(1)+x^{(0)}(2)+x^{(0)}(3)=196055.8$

$x^{(1)}(4)=x^{(0)}(1)+x^{(0)}(2)+x^{(0)}(3)+x^{(0)}(4)$

$$
=275306
$$

Step 3: The mean sequence $\mathrm{Z}^{(1)}$ of $\mathrm{X}^{(1)}$ is achieved as follows:

$Z^{(1)}(2)=\frac{1}{2} x^{(1)}(1)+x^{(1)}(2)=88652.45$

$Z^{(1)}(3)=\frac{1}{2} x^{(1)}(2)+x^{(1)}(3)=158848.3$

$Z^{(1)}(4)=\frac{1}{2} x^{(1)}(3)+x^{(1)}(4)=235680.9$

Step 4: Solving equations.

To find $a$ and $b$, the primitive series values are substituted into the Grey differential equation to obtain:

$$
\left\{\begin{array}{c}
121,640.80+a \times 88,652.45=b \\
196,055.8+a \times 158,848.3=b \\
275,306+a \times 235,680.9=b
\end{array}\right.
$$

convert the linear equations into the form of a matrix:

$$
\text { Let } B=\left[\begin{array}{ll}
-88652.45 & 1 \\
-158848.3 & 1 \\
-235680.9 & 1
\end{array}\right], \hat{\theta}=\left[\begin{array}{l}
a \\
b
\end{array}\right], Y_{N}=\left[\begin{array}{c}
65976.7 \\
74415 \\
79250.2
\end{array}\right]
$$

and then use the least square method to find $a$ and $b$

$$
\left[\begin{array}{l}
a \\
b
\end{array}\right]=\hat{\theta}=\left(B^{T} B\right)^{-1} B^{T} Y_{N}=\left[\begin{array}{c}
-0.09 \\
58742.89
\end{array}\right]
$$

use the two coefficients $a$ and $b$ to generate the whitening equation of the differential equation:

$\frac{d x^{(1)}}{d t}-0.09 \times x^{(1)}=58742.89$

find the prediction model from Equation:

$$
\begin{aligned}
& X^{(1)}(k+1)=\left(X^{(0)}(1)-\frac{b}{a}\right) e^{-a k} \frac{b}{a} \\
& x^{(1)}(k+1)=\left(55664.10-\frac{58742.89}{-0.09}\right) e^{0.090 \times k} \\
&+\frac{58742.89}{-0.09} \\
&=709,462.00 \times e^{0.090 \times k}-653797.90
\end{aligned}
$$

substitute different values of $\mathrm{k}$ into the equation:

$$
\begin{array}{ll}
\mathrm{k}=0 & X^{(1)}(1)=55664.1 \\
\mathrm{k}=1 & X^{(1)}(2)=122359.73 \\
\mathrm{k}=2 & X^{(1)}(3)=195325.33 \\
\mathrm{k}=3 & X^{(1)}(4)=275150.33 \\
\mathrm{k}=4 & X^{(1)}(5)=362479.59 \\
\mathrm{k}=5 & X^{(1)}(6)=458018.55 \\
\mathrm{k}=6 & X^{(1)}(7)=562539.02
\end{array}
$$

originate the predicted value of the original series according to the accumulated generating operation and obtain:

$\hat{x}^{(0)}(1)=x^{(1)}(1)=55664.1$

$\hat{x}^{(0)}(2)=\hat{x}^{(1)}(2)-\hat{x}^{(1)}(1)=66695.63$

$\hat{x}^{(0)}(3)=\hat{x}^{(1)}(3)-\hat{x}^{(1)}(2)=72965.60$

$\hat{x}^{(0)}(4)=\hat{x}^{(1)}(4)-\hat{x}^{(1)}(3)=79825.00$

$\hat{x}^{(0)}(5)=\hat{x}^{(1)}(5)-\hat{x}^{(1)}(4)=87329.25$

$\hat{x}^{(0)}(6)=\hat{x}^{(1)}(6)-\hat{x}^{(1)}(5)=95538.97$

$\hat{x}^{(0)}(7)=\hat{x}^{(1)}(7)-\hat{x}^{(1)}(6)=104520.46$.

The researchers use GM $(1,1)$ model to predict the realistic input/output factors for the next three years 2015 to 2017. Similarly to the above computation process, the study could get the forecasting results of all DMUs from 2015 and 2017. 


\subsection{Forecasting accuracy}

It is undeniable that forecasting always exists some errors; they are essentially about prediction the future in uncompleted information. Thus, in this paper, the MAPE (Mean Absolute Percent Error) is employed to measure the accuracy of a method for constructing fitted time series values in statistics (Nguyen and Tran, 2015). The value of MAPE is small, that means the forecasting value is typically close to the actual value. The result of MAPE Is shown in Table 2.

The calculations of MAPE are almost smaller than $10 \%$, especially the average MAPE of 18 DMUs reaches $4.03 \%$ (below $10 \%$ as well), it strongly confirms that the GM $(1,1)$ model provides a highly accurate prediction.

Table 2: Average MAPE error of all DMUs

\begin{tabular}{|c|c|c|c|}
\hline $\mathrm{DMU}_{\mathrm{s}}$ & Average MAPE & $\mathrm{DMU}_{\mathrm{s}}$ & Average MAPE \\
\hline $\mathrm{DMU}_{1}$ & $1.67 \%$ & $\mathrm{DMU}_{10}$ & $3.90 \%$ \\
\hline $\mathrm{DMU}_{2}$ & $3.15 \%$ & $\mathrm{DMU}_{11}$ & $0.93 \%$ \\
\hline $\mathrm{DMU}_{3}$ & $4.25 \%$ & $\mathrm{DMU}_{12}$ & $2.04 \%$ \\
\hline $\mathrm{DMU}_{4}$ & $3.22 \%$ & $\mathrm{DMU}_{13}$ & $7.59 \%$ \\
\hline $\mathrm{DMU}_{5}$ & $3.35 \%$ & $\mathrm{DMU}_{14}$ & $2.35 \%$ \\
\hline $\mathrm{DMU}_{6}$ & $1.33 \%$ & $\mathrm{DMU}_{15}$ & $4.30 \%$ \\
\hline $\mathrm{DMU}_{7}$ & $2.20 \%$ & DMU $_{16}$ & $14.32 \%$ \\
\hline $\mathrm{DMU}_{8}$ & $6.40 \%$ & $\mathrm{DMU}_{17}$ & $5.24 \%$ \\
\hline $\mathrm{DMU}_{9}$ & $4.58 \%$ & $\mathrm{DMU}_{18}$ & $1.76 \%$ \\
\hline \multicolumn{2}{|c|}{ Average MAPE of $18 \mathrm{DMU}_{\mathrm{s}}$} & \multicolumn{2}{|c|}{$4.03 \%$} \\
\hline
\end{tabular}

\subsection{DEA model selection}

DEA first developed by Charnes et al (1978) (CCR model), is a methodology for constructing a best practice frontier, which tightly envelops observed data on producers' inputs and outputs. Current research on DEA indicates that several potential models can be utilized to evaluate overall efficiencies of decision making units that are responsible to convert a set of inputs into a set of outputs. However, the efficient DMUs obtained in most DEA models like CCR and BCC cannot be compared and they do not accomplish the intended purpose in examining the EMSs because of these following reasons:

First, all conventional DEA techniques seem to lack objectivity by not representing the trueinput/output conditions for each DMU when they directly assign 'input-oriented' or 'outputoriented' models. In the two stage production process model used in this study, it's a difficult task to define input/output-oriented models without being subjective. In other words, non-radial measures should be the point of focus when aiming to achieve more realistic results because it directly deal with the excess input and the output shortfalls of the considered DMUs.

Second, the most significant problem when applying DEA model is to handle negative output/input data in the slacks-based measure models. As in some case, some variables are negative ones. Therefore, when engaging in performance evaluations, advanced techniques are required to handle with the negative output/input data in the slacks-based measure of super efficiency models.

Third, in this study the assets of the largest EMS companies are many times as large compared to smallest EMS companies. A small-sized DMU refers to the input/output allocation experiences of some super large-sized DMUs, which cannot be achieved in reality. Therefore, the results of the two stage models could be biased because of extreme values while forming an efficiency frontier to determine the efficiency score for each DMU.

Forth, engaging in DEA with a small number of DMUs compared to total criteria used for evaluation may lead to problems in determining which DMUs are the best performers. Hence, during examination the performance efficiency of 18 EMS companies, advanced techniques are required to sort out the best performers because in most DEA models, while the number of DMUs may be small, there will be multiple DMUs exhibiting an 'efficient' status with a score of one.

Therefore, when measuring the performance of EMS companies, the researcher applies advanced DEA techniques, slacks based measures of super efficiency (super SBM), as proposed by Tone in 2002 to evaluate EMSs performance by combining the profitability and the efficiency of marketability based on Seiford and Zhu's model (1998). When the number of DMUs is relatively small compared to evaluation criteria, the super SBM is very useful tool to help differentiate all the efficient DMUs. The author strongly consider that the super-SBM models used in the study results in acceptable and further convincing inquiry in the performance of EMS providers of transmutation of many inputs to many outputs. Cross-period efficiency analysis is also presented to decompose the inter-temporal efficiency change into 'catch-up' and 'frontier-shift' in accordance with the Malmquist index.

\subsection{Pearson correlation}

To apply DEA model, we have to make sure the relationship between input and output factors is isotonicity, which means if the input quantity increase; the output quantity could not decrease under the same condition. In this study, the researcher conducts a simple correlation test - 
Pearson correlation to measures the degree of association between two variables. Higher correlation coefficient means closer relation between two variables while lower correlation coefficient means that they are less correlated.

The interpretation of the correlation coefficient is explained in more detail as follows:

The correlation coefficient is always between -1 and +1 . The closer the correlation is to $+/-1$, the closer to a perfect linear relationship. Its general meaning was shown in Table 3.

Table 3: Pearson correlation coefficient Correlation coefficient $\quad$ Degree of correlation

\begin{tabular}{|c|c|}
\hline$>0.8$ & Very high \\
\hline $0.6-0.8$ & High \\
\hline $0.4-0.6$ & Medium \\
\hline $0.2-0.4$ & Low \\
\hline$<0.2$ & Very low \\
\hline
\end{tabular}

In the empirical study, the bellowing results indicate that the correlation well complies with the prerequisite condition of the DEA model because their correlation coefficient shows positive associations. As we can see from the Table 4, the correlation coefficient between input and output for the first stage is very high. All of them are more than 0.9 which show strong degree correlation. However, it can be seen that although all the factors are positively correlated, the figures for the second stage is quite low. Specifically the correlation between return on invested capitals with others input factors is less than 0.2 which is obviously much lower than the degree correlation among other factors in stage one but it does not violate the DEA model which cannot handle negative correlation. Therefore, these positive correlations also demonstrate clearly the fact that the researcher's choice of input and output variables at the beginning is appropriate. Obviously, none of variables removal is necessary.

\subsection{Performance rankings (Super-SBM)}

Table 4 summarizes the analysis process of December, 2014 data. They are set at value Returns to Scale $=$ Variable $($ Sum of Lambda $=1)$. Several authors such as Andersen and Petersen (1993), Doyle and Green (1994), Tofallis (1996), Seiford and Zhu (1999), Zhu (2002), Nguyen and Tran (2016), and Tone (2002) have proposed methods for ranking the best performers. The super-SBM model which was first proposed by Tone (2001) is an appropriate version of DEA for ranking these efficient EMS enterprises in this study. Several characteristics of the super-SBM model have been discussed before, especially its ability to cope with a small number of DMUs compared to the number of evaluation criteria.

In-order to differentiate those efficient EMS companies they considered as real benchmarks and for prioritizing and sequencing the super-SBM model is used. Because of the correlation between some of input and output variables in 2011 were negative, which does not fit the isotonicity assumption of DEA. Therefore, the authors only use the data from 2012 to 2014 to evaluate and rank the efficiency of 18 chosen EMSs. All of the results are shown in Table 4.

Table 4: Summary of super-SBM results of 2012, 2013 and 2014

\begin{tabular}{|c|c|c|c|c|c|c|}
\hline \multirow[b]{2}{*}{ 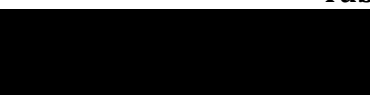 } & \multicolumn{2}{|c|}{2012} & \multicolumn{2}{|c|}{2013} & \multicolumn{2}{|c|}{2014} \\
\hline & stage 1 & stage 2 & stage 1 & stage 2 & stage 1 & stage 2 \\
\hline No. of DMUs in Data = 18 & 18 & 18 & 18 & 18 & 18 & 18 \\
\hline $\begin{array}{l}\text { No. of DMUs with } \\
\text { inappropriate Data }\end{array}$ & 0 & 0 & 0 & 0 & 0 & 0 \\
\hline No. of evaluated DMUs & 18 & 18 & 18 & 18 & 18 & 18 \\
\hline Average of scores & 1.222 & 0.867 & 1.266 & 0.839 & 1.252 & 0.798 \\
\hline No. of efficient DMUs & 13 & 7 & 12 & 7 & 11 & 7 \\
\hline No. of inefficient DMUs & 5 & 11 & 6 & 11 & 7 & 11 \\
\hline No. of over iteration DMUs & 0 & 0 & 0 & 0 & 0 & 0 \\
\hline
\end{tabular}

The results of super-SBM efficiencies were reported for both the profitability and marketability models in the Table 4 . It is clear that, there were significant fluctuation in the result of the amount of efficient and inefficient DMUs and the average of scores from 2012 to 2014. Some companies appeared efficient on stage one, other appeared efficient on stage 2 and the other had great results on both stages. In general, most companies had better performance on generating profit than increasing market value on the stock market. The number of enterprises which showed good performance for the profit generating stage decreased from 2012 to 2014 . The percentage of the efficient companies fell from $72 \%$ in 2012 to $66 \%$ in 2013 and then down to $61 \%$ in 2014 . In contrast, the figures kept quite stable for the second stage.
However, although in all three years the efficient ones maintained at 38\%, there are significant changes among efficient enterprises and their positions in the ranking in three years. Only four enterprises, which were Hon Hai Technology Co Ltd, Plexus, V.S. Industry and Wong's international Holdings Limited Company, exhibited efficient throughout 2012 to 2014. Hon Hai was the best performer for both profitability and marketability models with the highest leading score. Let's see deeper analysis in the next section. It can be easily obtained the productivity and marketability efficiency through the use of the DEA Solver software by Saitech in 1999. The super SBM is deployed here. The Table 5 shows the productivity and marketability of all 18 chosen EMSs from 2012 to 
Table 5: Super-SBM results of 2012, 2013 and 2014 of all DMUs

\begin{tabular}{|c|c|c|c|c|c|c|c|c|c|c|c|c|}
\hline \multirow{2}{*}{ DMUs } & \multicolumn{1}{c|}{ Productivity } & \multicolumn{1}{c|}{ Marketability } & \multicolumn{1}{c|}{ Productivity } & \multicolumn{2}{c|}{ Marketability } & \multicolumn{3}{c|}{ Productivity } & \multicolumn{2}{c|}{ Marketability } \\
\cline { 2 - 18 } & Score & rank & Score & rank & Score & rank & Score & rank & Score & rank & Score & rank \\
\hline DMU $_{1}$ & 4.734 & 1 & 1.764 & 1 & 4.763 & 1 & 1.772 & 1 & 4.478 & 1 & 1.767 & 1 \\
\hline DMU $_{2}$ & 1.072 & 8 & 0.531 & 16 & 1.429 & 3 & 0.498 & 15 & 1.306 & 5 & 0.594 & 9 \\
\hline DMU $_{3}$ & 1.441 & 3 & 0.691 & 10 & 1.340 & 4 & 0.560 & 14 & 1.588 & 3 & 0.623 & 8 \\
\hline DMU $_{4}$ & 0.874 & 14 & 0.828 & 8 & 0.908 & 14 & 0.728 & 8 & 0.874 & 14 & 0.575 & 10 \\
\hline DMU $_{5}$ & 0.770 & 16 & 0.399 & 18 & 0.790 & 17 & 0.485 & 16 & 0.810 & 15 & 0.420 & 16 \\
\hline DMU $_{6}$ & 1.085 & 7 & 0.649 & 13 & 0.990 & 13 & 0.591 & 13 & 1.049 & 9 & 0.493 & 13 \\
\hline DMU $_{7}$ & 1.039 & 11 & 0.649 & 12 & 0.814 & 16 & 0.618 & 10 & 1.141 & 6 & 0.511 & 11 \\
\hline DMU $_{8}$ & 0.334 & 18 & 1.374 & 2 & 0.263 & 18 & 1.504 & 2 & 0.417 & 18 & 1.342 & 3 \\
\hline DMU $_{9}$ & 1.063 & 9 & 1.183 & 4 & 1.032 & 10 & 1.432 & 3 & 0.875 & 13 & 1.609 & 2 \\
\hline DMU $_{10}$ & 1.039 & 12 & 0.772 & 9 & 1.090 & 9 & 0.598 & 11 & 0.955 & 12 & 0.498 & 12 \\
\hline DMU $_{11}$ & 1.249 & 4 & 1.179 & 5 & 1.274 & 5 & 1.065 & 6 & 1.320 & 4 & 1.013 & 6 \\
\hline DMU $_{12}$ & 1.062 & 10 & 0.581 & 14 & 1.123 & 7 & 0.377 & 17 & 1.108 & 7 & 0.439 & 14 \\
\hline DMU $_{13}$ & 0.808 & 15 & 0.545 & 15 & 1.027 & 11 & 0.258 & 18 & 0.723 & 16 & 0.404 & 17 \\
\hline DMU $_{14}$ & 0.616 & 17 & 1.280 & 3 & 0.875 & 15 & 1.137 & 5 & 0.704 & 17 & 1.140 & 5 \\
\hline DMU $_{15}$ & 1.620 & 2 & 0.454 & 17 & 1.841 & 2 & 0.597 & 12 & 2.116 & 2 & 0.420 & 15 \\
\hline DMU $_{16}$ & 1.014 & 13 & 1.002 & 7 & 1.021 & 12 & 1.012 & 7 & 1.091 & 10 & 1.002 & 7 \\
\hline DMU $_{17}$ & 1.100 & 5 & 0.666 & 11 & 1.131 & 6 & 0.706 & 9 & 1.081 & 8 & 0.368 & 18 \\
\hline DMU $_{18}$ & 1.092 & 6 & 1.059 & 6 & 1.093 & 8 & 1.178 & 4 & 1.014 & 11 & 1.154 & 4 \\
\hline
\end{tabular}

In 2012, the average scores computed from the super SBM models based on the profitability and marketability models were 1.222 and 0.867 , respectively. The result showed that eleven of the EMS companies which were efficient with all scores higher than one in the profitability performance field. The order of ranking in descending order was Hon Hai, PKC group, Flextronics, Venture, TT electronics, Wong's international company, Celestica, Pegatron Corp, Universal Scientific Industrial, SIIX, Benchmark Electronics, Plexus and V.S industry. Hon Hai got 4.734 which are almost fourth times the average score of 1.222 and much higher than other providers in the same industry. There were seven of the eighteen companies with efficiency scores of over one in the marketability performance field. The order of ranking was Hon Hai, Shenzhen Kaifa Technology, Fabrinet, Universal Scientific Industrial, Venture, Wong's international, V.S Industry. Table 6 indicates that the number of inefficient DMUs was 7 and 11 in first stage and second stage respectively. It is interesting that Shenzhen Kaifa Technology and Fabrinet had the second and the third highest score respectively on the second stage but they were in bottom in the ranking of efficiency in the first stage. It means that these two enterprises generated profit very effectively but they were less attractive in the stock markets. Jabil Circuit Inc, Sanmina and Integrated Micro-electronics, Inc. had inefficient results on both two stages. This clearly indicates that super-SBM can distinguish all DMUs with significant differences on their scoring. We can see the ranking more clearly in Fig. 3.

In 2013, 12 and 7 enterprises showed their improvement on efficiency on the first and second stage respectively. Hon Hai Technology Co Ltd, PKC Group, Pegatron Corp, Flextronics Intl Ltd and Venture stood in highest positions in first stage with score of $4.763,1.841,1.429,1.340$ and 1.274 respectively. Also in this stage, Shenzhen Kaifa Technology was the one that had lowest score at 0,263 . Seven enterprises which had score of higher than one in second stage were Hon Hai, Shenzhen Kafa Technology, Universal Scientific Industrial Co., Wong's international Holdings limited, Fabrinet, Venture and V.S industry.

Notice that Jabil Circuit Inc, Sanmina, Plexus and Integrated Micro-Electronics, Inc. did not performed well both in generating profit and in attracting stock market. Integrated Micro - electronics, Inc. stands at $18^{\text {th }}$ position in the ranking on in marketability performance with score of 0,258 . We can see the ranking more clearly in Fig. 4.

In 2014, it is obviously that the number of efficient EMSs in both stage 1 and stage 2 decreased in comparison with 2012 and 2013. There were only 11 and 7 efficient EMS providers in the profitability and the marketability model, respectively. Hon Hai had lower score compared to its score in past two years but it still was the best performer in this year. The order of ranking in descending order was Hon Hai Technology Co Ltd, PKC Group, Flextronics Intl Ltd, Venture, Pegatron Corp, Benchmark Electronics, SIIX, TT Electronics, Celestica and Wong's International Holdings Limited., etc., The super-SBM efficiency for the seven technically efficient EMS companies in the marketability performance model was also reported herein. The order of ranking was Hon Hai Technology Co Ltd, Universal Scientific Industrial Co., Ltd., Shenzhen Kaifa Technology, Wong's International Holdings Limited, Fabrinet, Venture and V.S. Industry. Shenzhen Kaifa Technology had the lowest score in the first stage and in the second stage; the lowest one belongs to TT Electronics with a score of 0.368 . We can see the ranking more clearly in Fig. 5.

After using GM $(1,1)$ to forecast all of the variables from 2015 to 2017 , the authors continuing 
assess the efficiency of all the 18 chosen EMS companies. The result is shown in Table 6 and 7. The

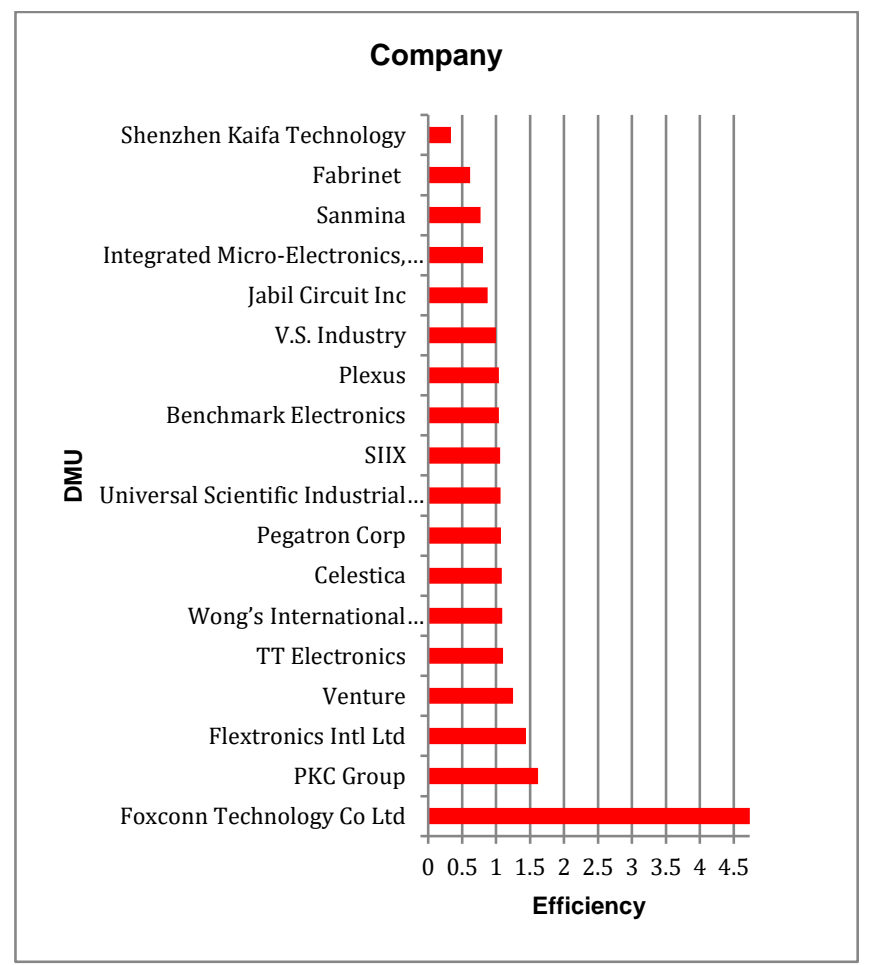

Profitability model bold ones mean efficiency scores.

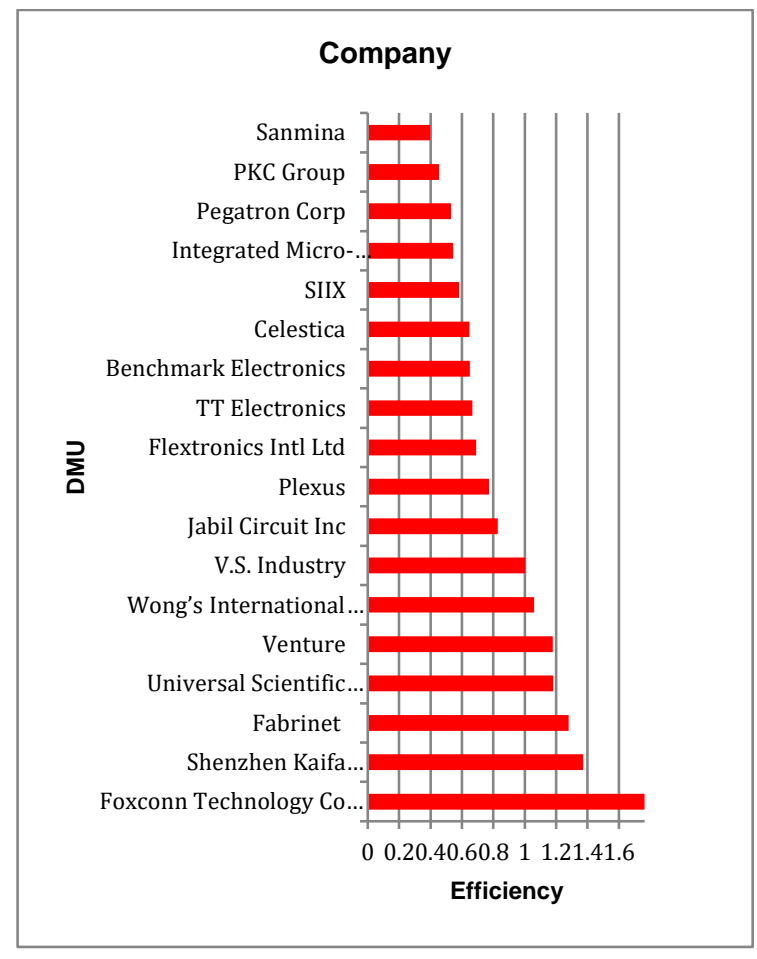

Marketability model

Fig. 3: Super-SBM results of 2012

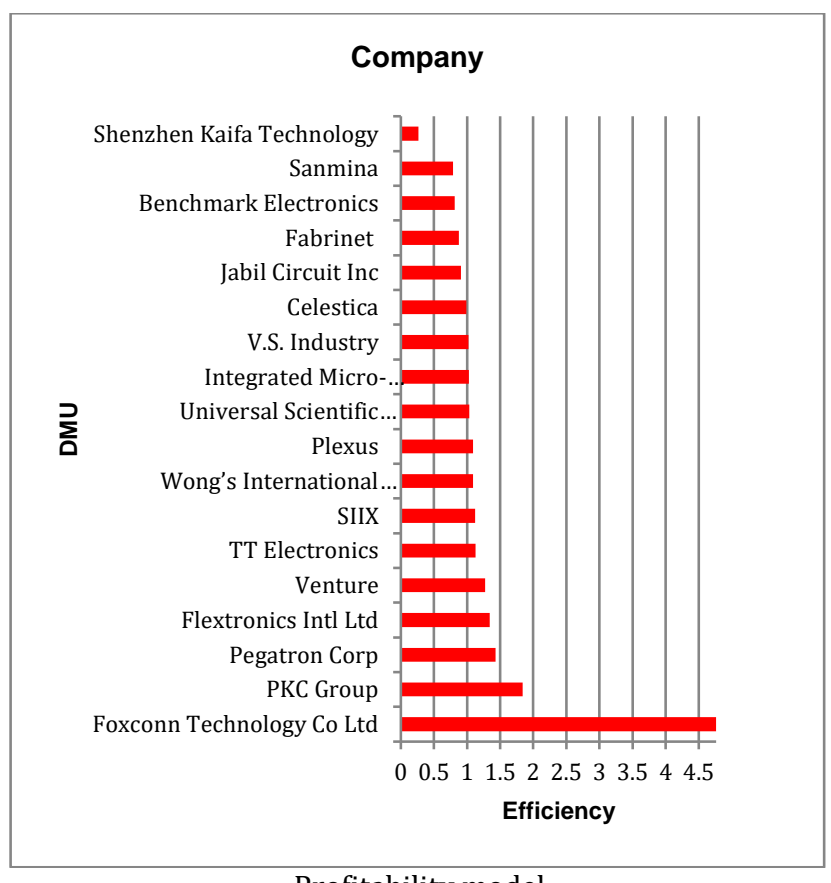

Profitability model

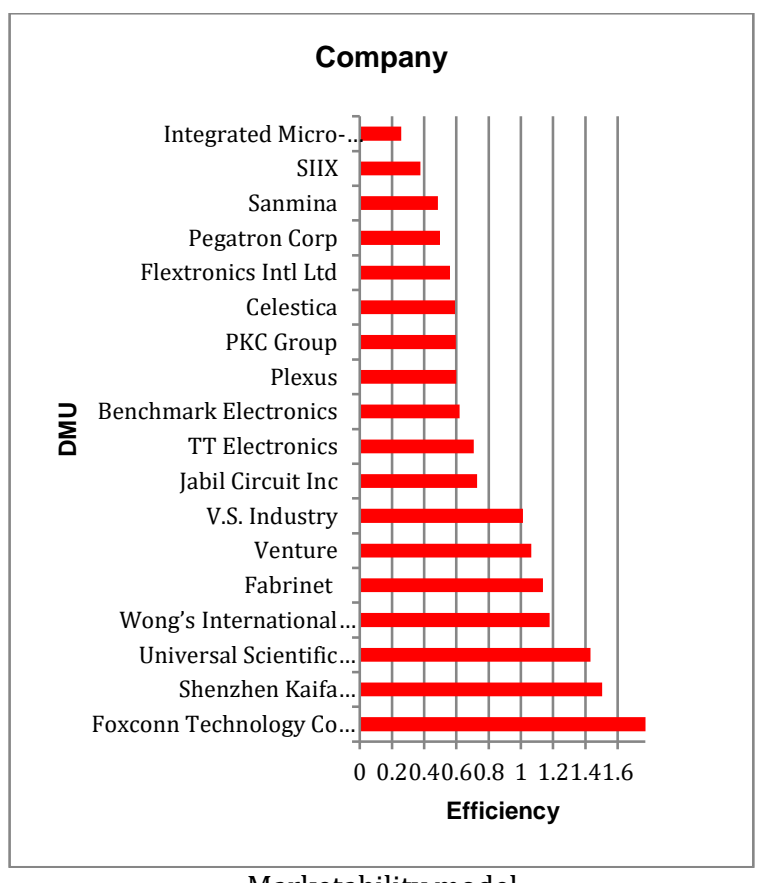

Marketability model

Fig. 4: Super-SBM results of 2013

There are some little changes in the average of scores and ranks among enterprises in comparison with the results in the past. It seems that the efficiency of both two stages of these companies will decrease in next three years. In other words, the ability to generate profit and increase market value or attraction to stock market is going down. However, the figures fluctuate year after year but the changes are not so much. For example, the average of score in 2012 was 1.222, it went up to 1.252 in 2014 and it is forecasted to be go down to 1.189 in 2015, drop off to 1.178 in 2016 and after that, in 2017 it will go up to 1.244 which is approximate to this figures of 2012. Changes seem to fluctuate widely in the second stage between past and future.

The average scores of second stage in 2012 was 0.867 and it declined to 0.798 on 2014 and is estimated to be sinking to 0.698 in 2017 . The order of efficiency ranking will have some changes in the next few years. 


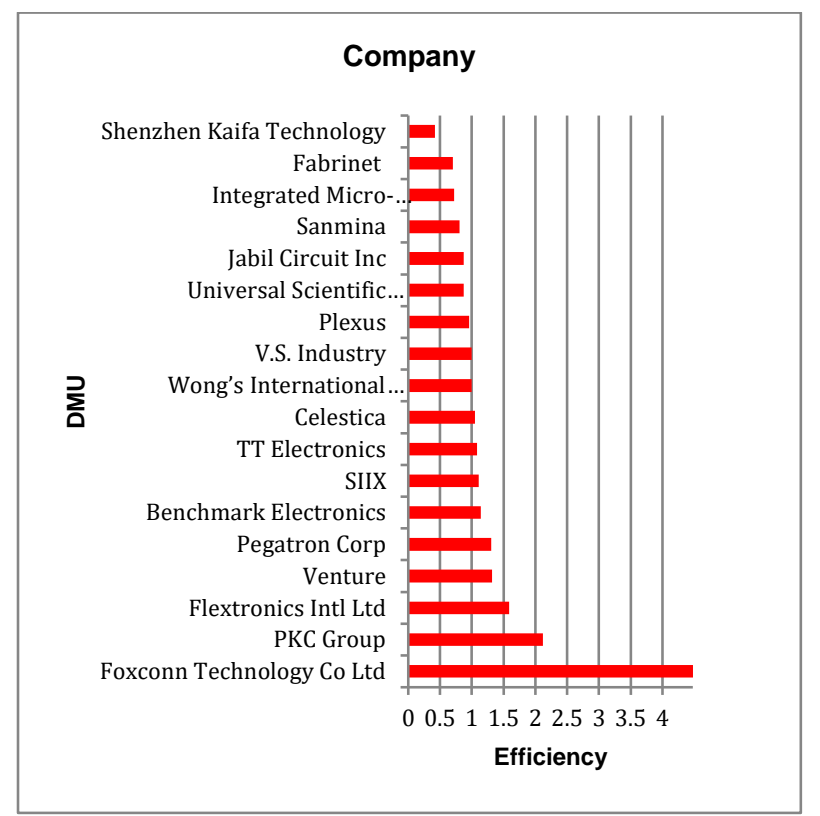

Profitability model

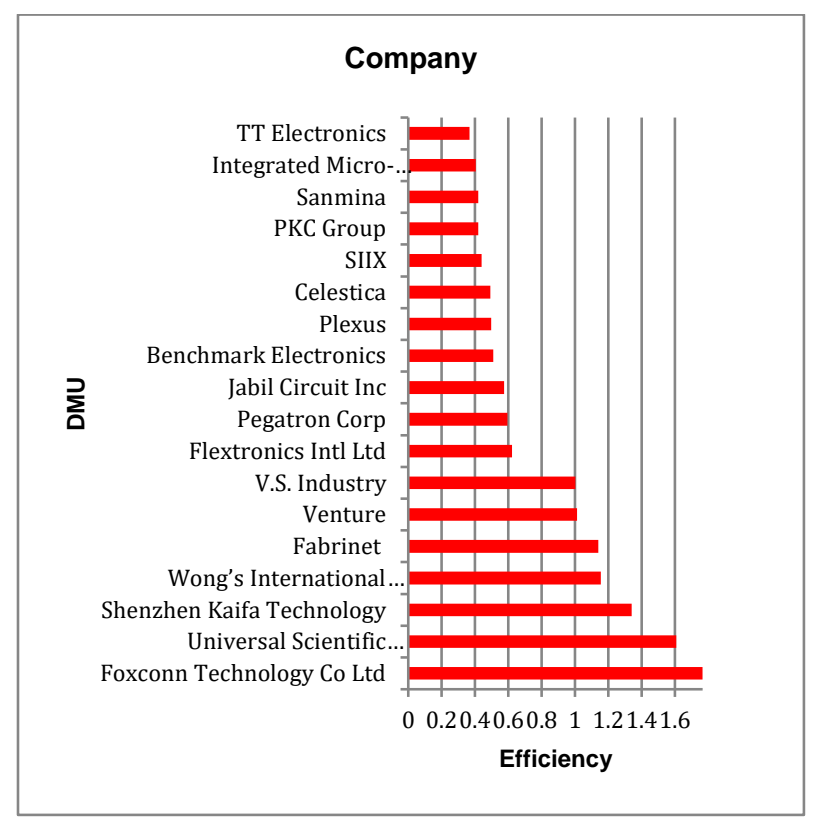

Marketability model

Fig. 5: Super-SBM results of 2014

Table 6: Summary of super-SBM results of 2015, 2016 and 2017

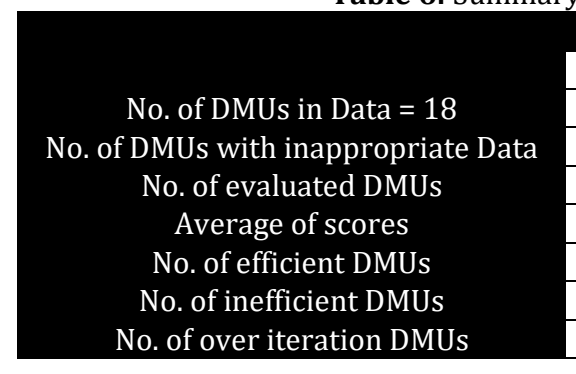
2015 2016 2017

\begin{tabular}{|c|c|c|c|c|c|}
\multicolumn{2}{|c|}{2015} & \multicolumn{2}{c|}{2016} & \multicolumn{2}{c|}{2017} \\
\hline stage 1 & stage 2 & stage 1 & stage 2 & stage 1 & stage 2 \\
\hline 18 & 18 & 18 & 18 & 18 & 18 \\
\hline 0 & 0 & 0 & 0 & 0 & 0 \\
\hline 18 & 18 & 18 & 18 & 18 & 18 \\
\hline 1.189 & 0.793 & 1.178 & 0.639 & 1.244 & 0.698 \\
\hline 12 & 7 & 11 & 5 & 11 & 6 \\
\hline 6 & 11 & 7 & 13 & 7 & 12 \\
\hline 0 & 0 & 0 & 0 & 0 & 0 \\
\hline
\end{tabular}

Table 7: Annual efficiency change from 2012 to 2014

\begin{tabular}{|c|c|c|c|c|}
\hline \multirow{2}{*}{ DMU } & \multicolumn{2}{|c|}{ Profitability } & \multicolumn{2}{|c|}{ Marketability } \\
\hline & $2012=>2013$ & $2013=>2014$ & $2012=>2013$ & $2013=>2014$ \\
\hline DMU1 & 1.006 & 0.940 & 1.005 & 0.997 \\
\hline DMU2 & 1.333 & 0.914 & 0.939 & 1.192 \\
\hline DMU3 & 0.930 & 1.185 & 0.811 & 1.113 \\
\hline DMU4 & 1.040 & 0.962 & 0.880 & 0.789 \\
\hline DMU5 & 1.026 & 1.025 & 1.216 & 0.866 \\
\hline DMU6 & 0.913 & 1.060 & 0.911 & 0.834 \\
\hline DMU7 & 0.783 & 1.402 & 0.952 & 0.827 \\
\hline DMU8 & 0.786 & 1.588 & 1.095 & 0.892 \\
\hline DMU9 & 0.971 & 0.848 & 1.211 & 1.124 \\
\hline DMU10 & 1.049 & 0.876 & 0.775 & 0.833 \\
\hline DMU11 & 1.020 & 1.036 & 0.904 & 0.951 \\
\hline DMU12 & 1.058 & 0.986 & 0.649 & 1.165 \\
\hline DMU13 & 1.270 & 0.704 & 0.473 & 1.568 \\
\hline DMU14 & 1.419 & 0.804 & 0.888 & 1.003 \\
\hline DMU15 & 1.136 & 1.149 & 1.315 & 0.704 \\
\hline DMU16 & 1.000 & 1.000 & 1.000 & 1.000 \\
\hline DMU17 & 1.028 & 0.956 & 1.061 & 0.521 \\
\hline DMU18 & 1.001 & 0.915 & 1.112 & 0.980 \\
\hline Average & 1.043 & 1.019 & 0.955 & 0.964 \\
\hline Max & 1.419 & 1.588 & 1.315 & 1.568 \\
\hline Min & 0.783 & 0.704 & 0.472 & 0.521 \\
\hline
\end{tabular}

However, some enterprises that are forecasted to have best perform in the first stage and second stage still are identified. Hon Hai, Pegatron, Flextronics, Plexu and Venture Corporation will be on the top five leading companies which will do well in generating profit and top five companies that are most attractive in the stock market are Hon Hai, Shenzhen Kaifa technology, Universal Scientific industrial Company, Wong's international holding and Pegatron. 


\subsection{EMSs' cross-period performance}

This study used DEA-Solver Pro 8.0 program built by Saitech company development to calculate each EMS providers' profitability and marketability efficiency by using input and output data which must be non-negative (greater than zero). In this study, all input and output are positive, which is satisfy the condition for using this software. This research primarily analyzed efficiency change and technical change for all EMS enterprises from 2012 to 2014 and from 2015 to 2017. After that, it analyzed Malmquist productivity index and found out the main reason of productivity decline of these two periods of time. This study also compares efficiency periods and productivity change across the field in order to understand the situation of every annual growth and decline of efficiency and productivity.

\subsubsection{Efficiency change}

In this section, the author will present the results of efficiency change scores, follows by a measure of productivity growth (MPI). The change in efficiency is called "catch-up" effect. The annual efficiency change index for each company is shown in Table 8. The bold figures show improvement in "catch-up" effect.

Table 8: Annual technical change from 2012 to 2014

\begin{tabular}{|c|c|c|c|c|}
\hline \multirow{2}{*}{ DMU } & \multicolumn{2}{c}{ Profitability } & \multicolumn{2}{c|}{ Marketability } \\
& $2012=>2013$ & $2013=>2014$ & $2012=>2013$ & $2013=>2014$ \\
\hline DMU1 & 1.012 & 1.060 & 0.998 & 1.103 \\
\hline DMU2 & 1.033 & 1.054 & 1.078 & 1.154 \\
\hline DMU3 & 0.916 & 0.951 & 1.042 & 1.162 \\
\hline DMU4 & 0.871 & 0.977 & 1.070 & 1.183 \\
\hline DMU5 & 0.992 & 0.998 & 1.369 & 1.288 \\
\hline DMU6 & 0.982 & 0.980 & 1.293 & 1.289 \\
\hline DMU7 & 1.037 & 0.943 & 1.323 & 1.143 \\
\hline DMU8 & 0.995 & 0.916 & 1.509 & 0.838 \\
\hline DMU9 & 1.017 & 0.947 & 1.020 & 1.139 \\
\hline DMU10 & 1.012 & 0.937 & 1.440 & 1.143 \\
\hline DMU11 & 1.008 & 0.977 & 1.103 & 1.085 \\
\hline DMU12 & 0.894 & 0.852 & 1.388 & 1.159 \\
\hline DMU13 & 0.890 & 0.920 & 1.135 & 1.080 \\
\hline DMU14 & 0.825 & 0.875 & 1.081 & 1.145 \\
\hline DMU15 & 0.743 & 1.160 & 1.088 & 1.149 \\
\hline DMU16 & 1.000 & 1.013 & 0.928 & 1.038 \\
\hline DMU17 & 0.952 & 0.923 & 1.049 & 1.159 \\
\hline DMU18 & 0.781 & 0.969 & 1.073 & 1.022 \\
\hline Average & 0.942 & 0.970 & 1.166 & 1.127 \\
\hline Max & 1.037 & 1.160 & 1.509 & 1.289 \\
\hline Min & 0.743 & 0.852 & 0.928 & 0.838 \\
\hline
\end{tabular}

The "catch - up" effect or also called the efficiency change relates to the degree to which a DMU improves or worsens its efficiency. Efficiency change $>1$ indicates progress in relative efficiency from 2012 - 2014, while efficiency change $=1$ and efficiency change $<1$ respectively indicate no change and regress in efficiency.

In profitability model, there were eleven companies with an efficiency change scores greater than 1 from 2012 to 2013 . These companies showed improvement in efficiency or in other words, showed improved their efficiency of generating profit between 2012 and 2013. Top 5 companies which had highest improvement were Fabrinet, Pegatron, Integrated Microelectronic, PKC and Plexus. Six companies which failed to improve their efficiency in this period of time were Flextronics, Celestica, Benchmark, Shenzhen Kaifa, Universal Scientific Industrial Co., and V.S Industry. Fabrinet had the largest improvement in technical efficiency with score of 1.419 while on the other hand Benchmark had the largest declines with score of 0.783 , followed by Shenzhen Kaifa with score of 0.786 in efficiency change. In marketability model, only eight companies showed improvement in efficiency. They were Hon Hai, Sanmina, Shenzhen Kaifa, Universal Scientific Industrial Co., PKC, TT electronics and Wong's international holding limited Company. Among them, PKC had the highest score with 1.315. The other twelve EMSs showed decline in efficiency. International Microelectronic had worst performance on this stage.

From 2013 to 2014, seven and six enterprises showed enhancement on efficiency on profitability and marketability model respectively. Flextronics, Sanmina, Celestica, Benchmark, Shenzhen Kaifa, Venture and PKC exhibited growth on generating profit and Pegatron, Flextronics, Universal Scientific Industrial Co., SIIX, Inter Microelectronic and Fabrinet showed improvement on attracting stock market. Shenzhen Kafa and Integrated Microelectronic had the largest improvement in efficiency in the first stage with score of 1.588 and second stage with score of 1.568 respectively. Although, Integrated Microelectronic seemed to be the most attractive in stock market with high score in marketability model but in fact they had low score in generating profit model. 
For the sampled periods as a whole, the average efficiency in both profitability and marketability decreased between two periods, from 2012 to 2013 and from 2013 to 2014 . In the first stage, the average score fell from 1.043 to 1.019 and fell from 0.955 to 0.964 in the second stage between two periods, which means that in general, EMSs had worse performance on generating profit and less effective in increasing market value recently.

\subsubsection{Technical change}

The second component of the Malmquist productivity change index is technical change, or the so-called "innovation" or "frontier-shift" effect. This component captures the effect of the frontier-shift of the productivity change of individual enterprise for an exposition of the effect of technical change on productivity change using production functions. A technical change is not necessarily technological as it might be organizational, or due to a change in a constraint such as regulation, input prices, or quantities of inputs. Annual technical change from 2012 to 2014 was shown in Table 9.

Table 9: Annual productivity change (MPI) from 2012 to 2014

\begin{tabular}{|c|c|c|c|c|}
\hline \multirow{2}{*}{ DMU } & \multicolumn{2}{|c|}{$\begin{array}{l}\text { Profitability } \\
\end{array}$} & \multicolumn{2}{|c|}{ Marketability } \\
\hline & $2012=>2013$ & $2013=>2014$ & $2012=>2013$ & $2013=>2014$ \\
\hline DMU1 & 1.018 & 0.996 & 1.002 & 1.100 \\
\hline DMU2 & 1.377 & 0.963 & 1.012 & 1.375 \\
\hline DMU3 & 0.852 & 1.127 & 0.845 & 1.293 \\
\hline DMU4 & 0.905 & 0.940 & 0.941 & 0.934 \\
\hline DMU5 & 1.017 & 1.023 & 1.666 & 1.116 \\
\hline DMU6 & 0.896 & 1.039 & 1.177 & 1.075 \\
\hline DMU7 & 0.812 & 1.323 & 1.260 & 0.945 \\
\hline DMU8 & 0.782 & 1.454 & 1.652 & 0.748 \\
\hline DMU9 & 0.988 & 0.803 & 1.235 & 1.280 \\
\hline DMU10 & 1.062 & 0.821 & 1.116 & 0.952 \\
\hline DMU11 & 1.028 & 1.011 & 0.997 & 1.032 \\
\hline DMU12 & 0.946 & 0.840 & 0.901 & 1.350 \\
\hline DMU13 & 1.131 & 0.648 & 0.536 & 1.693 \\
\hline DMU14 & 1.171 & 0.704 & 0.960 & 1.148 \\
\hline DMU15 & 0.844 & 1.334 & 1.430 & 0.809 \\
\hline DMU16 & 1.000 & 1.013 & 0.928 & 1.038 \\
\hline DMU17 & 0.979 & 0.883 & 1.113 & 0.604 \\
\hline DMU18 & 0.782 & 0.887 & 1.193 & 1.002 \\
\hline Average & 0.977 & 0.989 & 1.109 & 1.083 \\
\hline Max & 1.377 & 1.454 & 1.666 & 1.693 \\
\hline Min & 0.782 & 0.648 & 0.536 & 0.604 \\
\hline
\end{tabular}

We look at the technical change index. Table 9 reports the annual technical progress or regress. Technical change $>1$ stands for technical progress; Technical change $<1$ shows technical regress. The bold ones in the Table 9 show the improvement in technical change. It is clear that most of companies performed very well on frontier-shift effect. In the first stage, from 2012 to 2013, there were six companies which had technical change scores higher than one. They were Hon Hai, Pegatron, Universal Scientific Industrial Co., Plexus and Venture. There were twelve enterprises with a technical change scores smaller than 1 , which indicated the technical regress or innovation deteriorated in the period, meaning that there were not investment in new technologies (methodologies, procedures and techniques). Although, the others showed inefficient in this stage but they had relative high score which are almost one. PKC had the highest technical regress with score of 0.743 while on the other hand Benchmark had the highest progress with score of 1.037 in technical change. In the second stage, all the companies excluded Hon Hai and V.S Industrial Co. had score lower than one. However, these two companies also had very high score which was almost one, which means they had not too bad performance.
From 2013- 2014, the situation was quite the same with previous year. Only a few companies showed the improvement on technical change on the first stage and majority of them showed progress in the second stage. In profitability model, four providers which showed innovation in technical in the first stage was Hon Hai, Pegatron, PKC and V.S industrial Co. in the second stage, all companies excluded Shenzhen Kaifa Co. showed progress on technical change. Celestica had the highest technical progress with score of 1.289.

For the sampled periods as a whole, the average technical change increased in both two stages. Between period of 2012 - 2013 and 2013 - 2014, it rose from 0.942 to 0.970 in the first stage and decreased from 1.166 to 1.127 in the second stage.

\subsubsection{Productivity changes: the Malmquist productivity index and its decomposition}

Table 10 displays the annual productivity changes in the EMS industry over the period 20122014, as represented by the Malmquist non-radial productivity. As noted earlier, a greater-than-one Malmquist productivity index (MPI) denotes improvement in the productivity of EMS providers. Table 10 shows annual productivity change from 
Table 10: Cross-period performance (2012-2014)

\begin{tabular}{|c|c|c|c|c|c|c|c|c|c|c|c|c|}
\hline \multirow{3}{*}{ DMUs } & \multicolumn{12}{|c|}{ Cross-period performance (2012-2014) } \\
\hline & \multicolumn{6}{|c|}{ Profitability model } & \multicolumn{6}{|c|}{ Marketability model } \\
\hline & $\begin{array}{l}\text { Catch- } \\
\text { up }\end{array}$ & rank & Frontier & rank & Malmquist & rank & $\begin{array}{l}\text { Catch } \\
\text {-up }\end{array}$ & rank & Frontier & rank & Malmquist & rank \\
\hline DMU1 & 0.946 & 14 & 1.076 & 1 & 1.018 & 7 & 1.002 & 5 & 1.064 & 16 & 1.066 & 14 \\
\hline DMU2 & 1.218 & 3 & 1.011 & 2 & 1.232 & 1 & 1.119 & 2 & 1.226 & 11 & 1.372 & 3 \\
\hline DMU3 & 1.102 & 5 & 0.886 & 11 & 0.977 & 8 & 0.903 & 9 & 1.209 & 13 & 1.092 & 9 \\
\hline DMU4 & 1.000 & 10 & 0.860 & 12 & 0.860 & 12 & 0.694 & 16 & 1.273 & 7 & 0.884 & 17 \\
\hline DMU5 & 1.052 & 8 & 0.986 & 5 & 1.037 & 6 & 1.054 & 4 & 1.767 & 1 & 1.862 & 1 \\
\hline DMU6 & 0.967 & 13 & 0.990 & 4 & 0.958 & 9 & 0.759 & 13 & 1.660 & 2 & 1.261 & 4 \\
\hline DMU7 & 1.098 & 6 & 0.965 & 8 & 1.060 & 4 & 0.787 & 12 & 1.531 & 5 & 1.206 & 6 \\
\hline DMU8 & 1.248 & 2 & 0.900 & 10 & 1.123 & 2 & 0.977 & 7 & 1.116 & 15 & 1.090 & 10 \\
\hline DMU9 & 0.823 & 18 & 0.969 & 7 & 0.797 & 16 & 1.360 & 1 & 1.322 & 6 & 1.798 & 2 \\
\hline DMU10 & 0.919 & 15 & 0.977 & 6 & 0.898 & 10 & 0.645 & 17 & 1.659 & 3 & 1.070 & 13 \\
\hline DMU11 & 1.056 & 7 & 0.992 & 3 & 1.048 & 5 & 0.860 & 11 & 1.245 & 9 & 1.071 & 12 \\
\hline DMU12 & 1.043 & 9 & 0.775 & 16 & 0.808 & 15 & 0.756 & 14 & 1.604 & 4 & 1.213 & 5 \\
\hline DMU13 & 0.894 & 17 & 0.807 & 15 & 0.721 & 17 & 0.741 & 15 & 1.207 & 14 & 0.894 & 16 \\
\hline DMU14 & 1.142 & 4 & 0.725 & 17 & 0.828 & 14 & 0.890 & 10 & 1.222 & 12 & 1.088 & 11 \\
\hline DMU15 & 1.306 & 1 & 0.830 & 14 & 1.084 & 3 & 0.925 & 8 & 1.256 & 8 & 1.162 & 7 \\
\hline DMU16 & 1.000 & 10 & 0.597 & 18 & 0.597 & 18 & 1.000 & 6 & 1.033 & 18 & 1.033 & 15 \\
\hline DMU17 & 0.983 & 12 & 0.851 & 13 & 0.837 & 13 & 0.553 & 18 & 1.244 & 10 & 0.688 & 18 \\
\hline DMU18 & 0.916 & 16 & 0.942 & 9 & 0.863 & 11 & 1.090 & 3 & 1.051 & 17 & 1.145 & 8 \\
\hline Average & 1.040 & & 0.897 & & 0.930 & & 0.895 & & 1.316 & & 1.166 & \\
\hline
\end{tabular}

From 2012 to 2013, in the first stage, there were seven companies with a MPI values larger than 1 , which indicated that productivity growth in the period, the remaining eleven companies with a MPI less than 1, which indicates the loss of productivity. Pegatron had the highest productivity growth over the period 2012- 2013 with the score of 1.377 while on the other hand Shenzhen Kaifa Co. had the highest loss with the score of 0.782 . In contract, in the second stage, there were up to eleven enterprises exhibited growth in the productivity and only seven enterprises showed productivity loss. Sanmina had highest score which showed the best performance in generating profit. Integrated Microelectronic had highest productivity loss.

From 2013 to 2014, in the first stage, seven companies experienced productivity growth and other eleven showed loss productivity. Among them, Shenzhen Kaifa had highest productivity growth with score of 1.454 . In the second stage, there were twelve enterprises exhibited productivity growth, among them Integrate Microelectronic had highest score of growth (1.693) and TT electronic had highest score of productivity loss (0.604).

As mentioned in section2, given that the Malmquist productivity index of productivity change is a multiplicative composite of efficiency and technical change, the major cause of productivity improvements can be ascertained by comparing the values of the efficiency change and technique change indexes. Put differently, the productivity losses described can be the result of either efficiency declines, or technique regresses, or both. Crossperiod performances (2012-2014) are shown below.

Table 10 shows the efficiency change, technical change or what is named "catch-up" and "frontier" respectively over the yearly periods of time interval (2012-2014).
By taking the profitability model into consideration, the amount of EMS enterprises exhibit growth in terms of the catch-up effect is much higher than in frontier effect. Eleven providers that were Pegatron, Flextronics, Jabil Circuit Inc, Sanmina, Benchmark, Shenzhen Kaifa technology, Venture, SIIX, Fabrinet, PKC and V.S industry showed expansion in terms of catch-up, while only two out of eighteen companies experience improvement in term of frontier-shift effect. In other words, most of companies demonstrated a positive catch-up effect in devoting their efforts to catching up on the efficiency. Two large providers on EMS industry in this list, Hon Hai and Pegatron, which were on the efficiency frontier in the previous year, there was little room for improvement. On the other hand, due to the advantageous frontier-effect, two large EMSs break through the previous frontier in 2014, implying that the frontier moves forward due to the their better technological capability.

In marketability model, on the contrary with profitability model, all of EMSs showed the progress in term of frontier-shift effect. Only four companies show improvement on the degree of efforts that they attained for improving their efficiency.

Generally speaking, the trends in terms of the catch-up and frontier-shift effects found in EMSs are not consistent in both the profitability and marketability models.

Finally, the most important element in the performance evaluation of the industry is Malmquist productivity index (MPI). In general, most of the companies had a good performance in the second stage than in the first stage on period of time from 2012 to 2014 . While seven providers showed MPI> 1 on the profit generating stage, in marketability stage, there were up to fifteen companies which had productivity index larger than one. 
In this period of time, we notice that only DMU2 (Pegatron Corp) had best performance in all profitability, marketability and Malmquist index. Following are DMU1 (Hon Hai), DMU5 (Sanmina) which also exhibited growth this period.

In the first stage, productivity loss for Flextronics, Jabil, SIIX and Fabrinet was mainly driven by a decline of "frontier-shift" effect, or in other words, by a decline of technological regress, the result indicates that the company needs the product innovation or technology development to enhance production technology. The other companies' productivity loss was because of bad performance in both catch-up and frontier-shift effect, which means these companies not only need to reduce waste of input resources to enhance the profitability, but also have to possess the innovation to enhance production technology, from then level up the productivity in general. In the second stage, productivity change loss for Jabil, Integrated Microelectronic and TT electronic was the result of decreasing in catch-up effect, which showed that these companies still have great room for improvement and need to reduce waste of input resources to enhance the profitability.

For all of the observations, in the first stage, the average efficiency change and technique change were, respectively, 1.040 and 0.897 . Therefore, on average, the productivity change decreased with score of 0.930 because of bad innovation in technology rather than in technical efficiency. This result indicated that EMSs should pay attention to innovation to raise the profitability. In the second stage, the average efficiency change and technique change were 0.895 and 1.316 respectively and productivity change was 1.166 . This means that the innovation in technology lead to the productivity growth in EMSs. In general, both efficiency change and technical change had impact on the productivity in terms of contribution to MPI improvement. In other words, both catch-up and innovations (frontier-shift) effects were predominately attributed to EMS industry productivity growth. Cross-period performance Cross-period performance (2015-2017) is shown Table 11.

$\operatorname{GM}(1,1)$ handled the task of forecasting financial performance of the companies in the future. Obviously, we can see some significant changes of the industry in the forecasting period (2014-2017). In the first stage, seven enterprises which are Pegatron, Flextronics Shenzhen Kaifa, Plexus, Integrated Micro-electronics, PKC and IT electronic, will show improvement in term of catch-up effect. There are eleven companies will have efficient score in term of frontier-shift effect. In Malmquist Index, seven providers Pegatron, Benchmarks, Shenzhen Kaifa, Plexus, Venture, Integrated Micro-electronic and II electronics, will exhibit expansion in productivity. Among them, Plexus appears to have the highest potential with the score up to 3.137. In the second stage, only four companies show improvement in efficiency change. They are Pegatron, Jabil Circuit, Universal Scientifics industrial company, VS industry Berhad and Wong international holding limited company. It seems that, in this stage, all of companies pay attention to improve technical change in details and enhance productivity in general. That is the reason why there are up to sixteen efficient providers in term of frontier-shift effect and fifteen providers show expansion in productivity index. In general, some of enterprises like Pegatron Corp, Shenzhen Kafa Technology, Plexus and TT electronics appear as a very potential ones on generating profit. It is obvious that most of companies have better results than in the first stage, which indicates that EMSs are more and more attractive in the stock market and their market value are increasing rapidly.

\subsubsection{Managerial decision-making matrix}

In this part, a decision-making matrix is designed in order to help the EMSs' manager to identify their strength and weakness in the operation as well as their situation in the industry and to suggest some directions for improving operation efficiency.

The author will combine the results of the relative efficiency and productivity change analyses to get the result of this matrix.

Firstly, we assign productivity change in vertical coordinate in the matrix. A higher estimation signifies an efficient handling of resources, a higher degree of managerial efficiency in the previous year, and a greater development potential. In contrary, a lower estimation signifies an ineffective handling of resources in the previous years, a slight alteration in productivity, and decline in development potential. The cutting point is the score one derived from the Malmquist.

Secondly, the researcher use these findings in correspondence with relative efficiency on the profitability model of the current period (the year 2014) as the horizontal coordinate in the matrix, A higher estimation signifies good managerial efficiency at present so no urge for enhancement, however a lower estimation is a bad symptom and requires a need for enhancement. The cutting point is the score derived from the super- SBM measure. The decision-making matrix and the results of the analysis are shown in Fig. 5. This matrix is disseminated to 4 categories by means of 2 criteria: relative efficiency in current period (the managerial efficiency) and productivity variation across periods (the growth potential). This matrix can serve as a managerial decision-making matrix for further improvement efforts. The four groups of EMSs are described below:

- Group I: Companies in this category rejoice with good contemporary efficiency and enhanced variation in productivity. This group consists of: Hon Hai precision industry, Pegatron, Benchmark Electronics Inc, PKC group. These EMSs are forerunners for others and at present getting remarkable managerial efficiency and positive growth from the past. They continue to lead from 
the front if they take care the recommended raw materials and prevent major management errors.

- Group II: Companies in this category face worse contemporary efficiency, but an enhanced change in productivity. It consists of: Sanmina Corporation and Shenzhen Kaifa Technology. At present their inputs doesn't yield efficient outputs, but the measures taken over two years of time has some significant positive productivity. They may go to 'star group' in Group I only if the performance is improved. EMSs in this group ought to put much focus on matters that aimed at enhancing operational management.

- Group III: Companies in this category do so low both in terms of contemporary efficiency and variation in productivity. They include Jabil Circuit Inc, Universal Scientific Industrial Company,
Plexus, Integrated Micro-electronics and Fabrinet. In-order to cope up with industries in group I, it's necessary to begin enhancing their efficiency now, and to expand their productivity hereafter.

- Group IV: Companies in this category have better contemporary efficiency, but low productivity growth, are classified here. Seven of them, Flextronics, Venture Corporation Limited, SIIX Corporation, VS Industry, TT electronics and Wong's international Holdings Limited are in this group.Even though the above EMSs are the forerunners at present, they do not exhibit growth compared to the previous year. It is important for managers to find out some strategies to actively expand their business in order to increase productivity.

Table 11: Cross-period performance (2015-2017)

\begin{tabular}{|c|c|c|c|c|c|c|c|c|c|c|c|c|}
\hline \multirow{2}{*}{ DMUs } & \multicolumn{6}{|c|}{ Profitability model } & \multicolumn{6}{|c|}{ Marketability model } \\
\hline & $\begin{array}{c}\text { Catch- } \\
\text { up }\end{array}$ & rank & Frontier & rank & Malmquist & rank & $\begin{array}{c}\text { Catch- } \\
\text { up }\end{array}$ & rank & Frontier & rank & Malmquist & rank \\
\hline DMU1 & 0.819 & 16 & 1.176 & 1 & 0.963 & 10 & 0.837 & 8 & 1.229 & 15 & 1.029 & 14 \\
\hline DMU2 & 1.138 & 2 & 1.032 & 5 & 1.174 & 2 & 1.589 & 2 & 1.295 & 14 & 2.058 & 2 \\
\hline DMU3 & 1.020 & 5 & 0.935 & 15 & 0.954 & 12 & 0.706 & 12 & 1.571 & 9 & 1.109 & 12 \\
\hline DMU4 & 0.884 & 14 & 0.917 & 16 & 0.811 & 17 & 2.166 & 1 & 1.298 & 13 & 2.812 & 1 \\
\hline DMU5 & 0.890 & 13 & 1.117 & 3 & 0.994 & 8 & 0.895 & 6 & 1.899 & 6 & 1.700 & 3 \\
\hline DMU6 & 0.854 & 15 & 1.119 & 2 & 0.956 & 11 & 0.699 & 13 & 1.899 & 6 & 1.327 & 8 \\
\hline DMU7 & 0.997 & 9 & 1.015 & 9 & 1.013 & 6 & 0.727 & 11 & 1.566 & 10 & 1.138 & 10 \\
\hline DMU8 & 1.106 & 3 & 1.025 & 7 & 1.133 & 3 & 0.799 & 9 & 2.089 & 3 & 1.669 & 4 \\
\hline DMU9 & 0.781 & 17 & 1.081 & 4 & 0.844 & 15 & 1.016 & 4 & 1.501 & 11 & 1.524 & 5 \\
\hline DMU10 & 3.116 & 1 & 1.007 & 11 & 3.137 & 1 & 0.536 & 15 & 2.050 & 4 & 1.098 & 13 \\
\hline DMU11 & 0.979 & 10 & 1.023 & 8 & 1.001 & 7 & 0.354 & 17 & 2.843 & 1 & 1.006 & 15 \\
\hline DMU12 & 0.973 & 11 & 0.953 & 14 & 0.928 & 13 & 0.606 & 14 & 2.326 & 2 & 1.411 & 7 \\
\hline DMU13 & 1.084 & 4 & 0.990 & 12 & 1.074 & 4 & 0.797 & 10 & 1.833 & 8 & 1.461 & 6 \\
\hline DMU14 & 0.973 & 11 & 0.841 & 18 & 0.819 & 16 & 0.506 & 16 & 1.178 & 16 & 0.596 & 17 \\
\hline DMU15 & 1.000 & 6 & 0.987 & 13 & 0.987 & 9 & 0.863 & 7 & 1.313 & 12 & 1.133 & 11 \\
\hline DMU16 & 0.543 & 18 & 1.027 & 6 & 0.558 & 18 & 1.000 & 5 & 0.373 & 18 & 0.373 & 18 \\
\hline DMU17 & 1.000 & 6 & 1.014 & 10 & 1.014 & 5 & 0.338 & 18 & 2.006 & 5 & 0.679 & 16 \\
\hline DMU18 & 1.000 & 6 & 0.891 & 17 & 0.891 & 14 & 1.301 & 3 & 0.952 & 17 & 1.238 & 9 \\
\hline Average & 1.064 & & 1.008 & & 1.069 & & 0.874 & & 1.662 & & 1.298 & \\
\hline
\end{tabular}

\section{Research conclusions}

In this research, the performance of 18 EMS providers was evaluated by adopting Seiford and Zhu's two-stage profitability and marketability model (Seiford and Zhu, 1999). Profitability is the main financial goal of all business activities or ventures. It is usually defined as the ability of a given investment to earn a return on its use. Profitability also determines the survival of the business in the long run. Thus measuring and assessing profitability is very important. However, it is undeniable that profitability (profit generating) efficiency is essential for a company, marketability (market value increasing) efficiency is also important for all EMS providers given the fact that the real value of the company should be ultimately defined by the current stock market. Unlike most of other researches which just focus on profitability, the two-stage production processes model are also applied herein to ensure both profit generating (profitability) and market value increasing (marketability) efficiency are not neglected. The profitability is calculated in the first stage with three inputs: employees, assets and equity that produce outputs revenue and profit. The marketability of those companies is measured in the second stage by using two inputs revenue and profit that produce two outputs: market value and return on capital. Revenues and profits, which are considered as intermediate products, are the outputs of the first stage as well as the inputs of the second stage. The efficiencies of the first stage (profitability) and second stage (marketability) are calculated separately via two independent DEA models for ranking and assessing the efficiency of EMSs.

On Seiford and Zhu's research on large US banks (Seiford and Zhu, 1999), they apply traditional DEA methods to investigate the performance efficiency of large US banks. Different from their investigation, to avoid the disadvantage of traditional DEA which did not take an account of slacks directly, the author apply the methods of Super SBM which is expected to get more persuasive and higher valid results in measuring EMSs' efficiency. The efficiency change, 
technical change and productivity change of crossperiod were also reported herein based on the nonradial Malmquist index.

The main results of this research are followings. First, the efficiency of 18 EMS providers in both profitability and marketability model were not consistent. It changed from time to time and did not depend on the size of the providers. In other words, it is not true to say that larger-sized EMSs performed better than the smaller-sized ones or vice versa. The small enterprises absolutely could exhibit higher profitability efficiency and get more attention from investors if they could show their ability and development potential. Secondly, the ranking of efficient EMSs each year from the highest to the lowest was reported to identify the best performers. The forecasted results of the year from 2015 to 2017 also reported herein. Although the total efficient DMUs did not change so much but the order of ranking showed big difference among these EMSs from year to year. Thirdly, when considering performance of each year with super SBM, the efficiency of profitability stage is higher than in marketability, which means most of companies invest great effort on generating profit and gained good results. Hon Hai keeps its champion position all the times. Fourthly, in the cross period efficiency analysis with Malmquist, for the period of 2012 to 2014, the number of companies which show improvement in MPI of the second stage is higher than in the first stage, which means that productivity of increasing market value or the attractiveness in the stock market of these EMS providers in this period of time is better than generating profit. In the next three year (2015-2017), it is forecasted that the situation will be the same with previous period, however, there will be more providers showing efficiency in Malmquist index in the profitability model when comparing with the past. The number of enterprises exhibiting growth in the first stage is still lower than in the second stage, which urges an improvement on generating profit ability.

The main contributions of this study are shown as follows:

This study give a better insight of operational performance decomposition in a two-stage production process of EMSs in recent year and in next few year with the combination of using DEA and Grey method.

A decision making matrix is designed with the combination of current relative efficiency and productivity change to help the EMSs' managerial authorities to position themselves in the industry, from then, to develop the effective strategies for the growth.

From a researcher's point of view, it is hoped that the integration of the models proposed in this study can be applied to other similar industries to evaluate operational efficiency and determine means for improvement.

\section{References}

Andersen P and Petersen NC (1993). A procedure for ranking efficient units in data envelopment analysis. Management Science, 39(10): 12611264.

Charnes A, Cooper WW and Rhodes E (1978). Measuring the efficiency of decision making units. European Journal of Operational Research, 2(6): 429-444.

Doyle J and Green R (1994). Efficiency and crossefficiency in DEA: Derivations, meanings and uses. Journal of the Operational Research Society, 45(5): 567-578.

Golany B and Roll Y (1989). An application procedure for DEA. Omega, 17(3): 237-250.

Julong D (1989). Introduction to grey system theory. The Journal of Grey System, 1(1): 1-24.

Nguyen NT and Tran TT (2015). Mathematical development and evaluation of forecasting models for accuracy of inflation in developing countries: A case of Vietnam. Discrete Dynamics in Nature and Society, 2015: Article ID 858157. https:// doi.org/10.1155/2015/858157

Nguyen NT and Tran TT (2016). Facilitating an advanced product layout to prioritize hot lots in $450 \mathrm{~mm}$ wafer foundry in the semiconductor industry. International Journal of Advanced and Applied Sciences, 3(6): 14-23.

Nguyen NT, Tran TT, Wang CN and Nguyen NT (2015). Optimization of strategic alliances by integrating DEA and grey model. Journal of Grey System, 27(1): 38-56.

Seiford LM and Zhu J (1998). Stability regions for maintaining efficiency in data envelopment analysis. European Journal of Operational Research, 108(1):127-139.

Seiford LM and Zhu J (1999). Profitability and marketability of the top 55 US commercial banks. Management Science, 45(9): 1270-1288.

Tofallis C (1996). Improving discernment in DEA using profiling. Omega, 24(3): 361-364.

Tone K (2001). A slacks-based measure of efficiency in data envelopment analysis. European Journal of Operational Research, 130(3): 498-509.

Tone K (2002). A slacks-based measure of superefficiency in data envelopment analysis. European Journal of Operational Research, 143(1): 32-41.

Zhu J (2014). Quantitative models for performance evaluation and benchmarking: data envelopment analysis with spreadsheets. Springer, Academic Publishers, Boston, USA: 213. 